\title{
Las vueltas de El Mito Gaucho
}

Nora Andrea Bustos

Em 1948, o filósofo argentino Carlos Astrada interpretou em sua obra El mito gaucho, reeditada em 1964, o poema "Martín Fierro" como expressão do "mito da nação". Este artigo demonstra que Astrada atrelou sua análise às mudanças da conjuntura política associando os que assumiam o poder à figura imaginária do "herói nacional".

Palavras-chave: Mito, Nação, Gaucho, Herói.

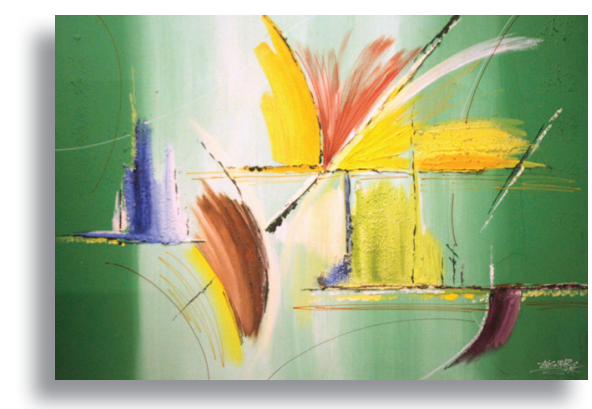

\section{The twist and turns of the Gaucho Myth}

In 1948, the Argentine philosopher Carlos Astrada interpreted in his work The Gaucho Myth, reprinted in 1964, the poem "Martín Fierro" as an expression of "the myth of the nation." This article demonstrates that Astrada pegged his analysis to changes in political conjuncture associating those who assumed power to the imaginary figure of the "national hero".

Key words: Myth, Nation, Gaucho, Hero.

\footnotetext{
Nora Andrea Bustos:

Pesquisadora do Conselho Nacional de Pesquisas Científicas e Tecnológicas e do Instituto de Investigaciones Gino Germani, doutoranda em Ciências Sociais da Universidade de Buenos Aires, docente da Universidade Nacional de Mar del Plata e da Universidade de Ciências Empresariais e Sociais.
} 


\section{INTRODUCCIÓN}

Este trabajo tiene como propósito ofrecer el análisis de la obra de Carlos Astrada, El mito gaucho, en las dos ediciones que estuvieron a su cuidado. Para ello tomaremos la primera edición del año 1948, el contexto político de su surgimiento y la relación de este contexto con el contenido de sus ideas. Luego haremos referencia a los caminos que siguieron los principales conceptos de dicha obra en relación al periplo intelectual y político del filósofo. Por último, traeremos a colación la segunda edición del año 1964, a partir de la cual reflexionaremos sobre los cambios que contiene el trabajo original, señalando que sus tesis principales, a pesar del viraje político del autor, se mantienen.

La aparición de El mito gaucho acontece en un momento en que el Estado se hallaba peculiarmente emparentado con la filosofía. La primera presidencia de Juan Domingo Perón, a quien Astrada admiraba profundamente por entonces, estuvo muy fuertemente vinculada a un grupo de intelectuales que acompañaron y fundamentaron las decisiones de su gobierno. En este contexto la aparición de la obra de Astrada expresó el intento de configurar una comunidad nacional, alrededor de una determinada interpretación del "Martín Fierro". ${ }^{1}$ El poema nacional, según Astrada, contiene los lineamientos esenciales del pueblo argentino, el cual reclama su reconocimiento como tal. Luego de haber sido vituperadas las clases subalternas, el gaucho Martín Fierro representa al campesino maltratado y ninguneado por el Estado, la policía y la oligarquía, que es conducido a una vida hostil y llena de desgracias si bien, no obstante, promueve y exhorta a sus hijos a pelear por los ideales de una sociedad más justa. Es así que el propio Astrada afirma en su primera edición que el 17

1 Este poema narra la historia del gaucho Martín Fierro quien es obligado a prestar servicios en la lucha contra el indio y rápidamente se convierte en un desertor. Su fuga dura diez años en la frontera, en los que atraviesa toda clase de vicisitudes. Martín Fierro, acompañado por su guitarra, relata sus peripecias reflejando de este modo la realidad del gaucho matrero, que se mete en problemas permanentemente y la única forma que encuentra para deshacerse de los mismos es la huída. La policía se muestra corrupta y discriminadora, de ahí sale Cruz, su compañero de viaje, tras desertar de sus servicios. El poema consta de dos partes que fueron escritas en distintas épocas. "La ida", de 1872, narra la vida del gaucho junto con el indio, la que no deja de estar plagada de infortunios y enfrentamientos. "La vuelta", publicada siete años después, contiene el reencuentro de Martín Fierro con sus hijos, y los relatos de cómo fueron los diez años de vida de cada uno. Su hijo mayor narra su encarcelamiento injusto y todos los padecimientos que tuvo que soportar por parte de la policía. Su hijo menor cuenta el modo en que cayó en manos de un viejo tutor llamado Vizcacha, quien aparte de aprovecharse de su situación particular, pretendió impartirle una moral pragmatista que consistía en el acomodo y la corrupción para conseguir los objetivos que se propusiera. No obstante, Martín Fierro culmina aconsejando a sus hijos que trabajen para construir una sociedad más justa, en la que nadie tenga que soportar los tormentos que a ellos le han tocado y en la que no haya ni excluidos ni perseguidos. 
de octubre fue el día que el mito renació, pues aparecieron Los hijos de Fierro $^{2}$ representando de alguna manera a los desclasados que configurarían la nueva comunidad nacional. ${ }^{3}$

En un día de octubre de la época contemporánea, día luminoso y templado, en que el ánimo de los argentinos se sentía eufórico y con fe renaciente en los destinos nacionales, aparecieron en escena, dando animación inusitada a la plaza pública, los hijos de Martín Fierro (ASTRADA, 1948 a, p. 94).

Astrada afirma que en el "Martín Fierro" está expresado el mito de los argentinos, el cual emerge desde la tierra con un mensaje telúrico que conlleva el numen de la nacionalidad. El gaucho Martín Fierro constituye el héroe en el que se encarnó el mito, pues es el ejemplo del gaucho que luchó por la independencia nacional. Pero el mito retorna una y otra vez escogiendo nuevos héroes.

Para Astrada, el gaucho, quien contiene la sangre del indio, fue el protagonista de las luchas por la independencia nacional. De este modo el paria espoleado y desacreditado por las clases dominantes es precisamente aquel que contiene el mayor tesoro: el germen de la argentinidad.

Catorce años después, Astrada - alejado totalmente del peronismo - vuelve a editar esta obra, pero ahora apelando a la insurrección agraria para la conformación de lo que él llama un "auténtico pueblo argentino", que ha sido engañado por un "pseudojefe"4 que se proponía como conductor del pueblo. Es así que esta segunda edición tiene de trasfondo relaciones políticas de Astrada totalmente diferentes, las cuales irán desde su entrevista con Mao-Tsé Tung en China hasta su relación con Mario Roberto Santucho. ${ }^{5}$ Pero sin embargo, la principal tesis de la obra se mantendrá intacta. Definitivamente hay un mito de la nación, el cual ha quedado fielmente expresado en

2 El film de Pino Solanas "Los hijos de Fierro" está basado en parte en este libro.

3 El día 17 de octubre de 1945 millones de personas se concentraron en la Plaza de Mayo reclamando la liberación del coronel Juan Domingo Perón, quien había sido apresado por defender los derechos de los trabajadores. Para muchos autores, este acontecimiento abre un nuevo escenario político en la Argentina nunca antes visto. Y es porque entran en la escena política aquéllos sectores populares que habían sido relegados por los diferentes gobiernos. El protagonismo de esos sectores tuerce el rumbo que tomará la política argentina. Perón será el presidente del movimiento de masas más imponente de la historia de este país. Al 17 de octubre se lo recuerda como "Día de la Lealtad" y en la actualidad se realizan numerosos actos en su conmemoración.

4 Se refiere a Juan Domingo Perón.

5 Mario Roberto Santucho (1936-1976) fue el fundador del Partido Revolucionario de los Trabajadores y comandante del Ejército Revolucionario del Pueblo, una de las mayores guerrillas marxistas de Argentina. 
el Martín Fierro, que emerge de la tierra para dar un mensaje de construcción colectiva y que lleva el germen del destino de la nación.
Los hermanos sean unidos porque esa es la ley primera tengan unión verdadera en cualquier tiempo que sea porque si entre ellos pelean los devoran los de ajuera (HERNÁNDEZ, 2005, p. 202)

\section{SEMBLANZA DE CARLOS ASTRADA}

Carlos Astrada fue un pensador argentino que tuvo una considerable relevancia en determinados momentos clave del siglo veinte en nuestro país y en el mundo. Podríamos decir que fue uno de los personajes que hizo que en otros lugares se hablara de que había algo así como una "filosofía argentina".

El filósofo nació en el año 1894. Ingresó a la Universidad como estudiante de Derecho, carrera que abandona por una riña con un profesor. No obstante su concurrencia a la Universidad fue decisiva, respecto a su participación en la Reforma Universitaria, pero pronto rompió con el movimiento. La primera acción que lo hace entrar en polémica con las principales corrientes de la Reforma es el saludo que hiciera a la Revolución Rusa en el primer aniversario de la misma.

Carlos Astrada, así como otros participantes activos de la Reforma, fue un intelectual prolífero desde temprana edad. En el año 1920 es nombrado director de Publicaciones en la Biblioteca de la Facultad de Derecho y Ciencias Sociales de la Universidad Nacional de Córdoba. Allí traduce el artículo "El conflicto en la cultura moderna" de Georg Simmel.

En 1927 obtiene una beca para estudiar en Alemania la cual lo lleva a conectarse con los principales exponentes de la fenomenología y la filosofía de la existencia. Al llegar a Alemania se instala en Colonia donde cursa seminarios con Nicolai Hartmann y Max Scheler, de quien extrae el concepto de "hombre plenario" y con quien traba una corta, pero profunda amistad. Un tiempo después el maestro fallece y ante este suceso, Astrada continúa sus estudios con Martín Heidegger.

De regreso a la Argentina publica el artículo "Hegel y el presente" en donde manifiesta la vigencia de la dialéctica como modo de entender la historia y la necesidad de integrar en el desarrollo de este pensamiento la filosofía de la existencia heideggeriana. Luego de publicar una 
importante cantidad de artículos sale su primer libro El juego existencial, de 1933. Allí Astrada plantea el carácter lúdico de la interrogación por el ser. Al poco tiempo pronuncia su conferencia sobre Heidegger y Marx en donde comienza a expresar su intento de abordar el marxismo desde la filosofía de la existencia, viendo una íntima conexión entre el homo eoconomicus de Marx y el homo curans postulado por Heidegger.

En 1935 es nombrado profesor adjunto de Historia de la Filosofía Moderna y Contemporánea en la Facultad de Filosofía y Letras de la Universidad Nacional de Buenos Aires y un año después publica su segundo libro, Idealismo fenomenológico y metafísica existencial. Al año siguiente se instala con su familia en Buenos Aires y edita su obra La ética formal y los valores, con la que obtiene el Segundo Premio Nacional de Filosofía. El año 1942 será el de la publicación de su cuarto libro El juego metafísico. Aquí ya aparece el concepto de "mito" como aquello que repone la noción abismal de la incertidumbre del jugador. En 1943 aparece Temporalidad, un libro donde recoge su labor estética e historicista de sus primeros pasos filosóficos. Al cumplirse el bicentenario del natalicio de Herder, en 1944, brinda una conferencia sobre el filósofo en el Colegio Libre de Estudios Superiores. De este pensador extrae su visión romántica de que la felicidad de los seres humanos está dada en su participación en el desarrollo de cada pueblo como nación, cuestión que recorrerá toda su obra. Su libro Nietzsche, profeta de una edad trágica, de 1945, constituye la plasmación de la recepción que en la obra de Astrada venía operando este pensador.

Tras la asunción de Perón al poder, el movimiento buscó asentarse en las Universidades, encontrando apoyo en ciertos sectores nacionalistas católicos o irigoyenistas que habían quedado al margen de la conducción universitaria. A estos se sumó el propio Astrada por voluntad personal. La Ley 13.031 facultaba al Poder Ejecutivo para designar a los profesores universitarios luego del concurso público. Así, Astrada accede al cargo de titular de Gnoseología y Metafísica de la Facultad de Filosofía y Letras de la Universidad Nacional de Buenos Aires. A partir del año 1946 el filosofar de Astrada estará teñido por el entusiasmo que le propiciara el auge del peronismo. Es en este marco que verá la luz El mito gaucho.

Un año más tarde Astrada organiza el Primer Congreso Internacional de Filosofía el cual contó con figuras destacadas de todo el mundo. Hasta el entonces presidente Perón estaba presente con su conocida disertación "La comunidad organizada". La repercusión que tuvo este congreso fue descollante. Meses después Wilhem Szilazi le envió una invitación 
a Astrada con motivo de la celebración del sexagésimo cumpleaños de Heidegger, solicitándole además un texto para conmemorar el evento. Astrada le responderá con un artículo titulado "Hacia una praxis histórico existencial" en donde plantea la posibilidad de una proyección revolucionaria en el existencialismo. Años después el mismo Heidegger lo invitó a pronunciar esta disertación en su cátedra de la Albert Ludwig Universität.

Aprovechando su año sabático Astrada vuelve a Europa. Recorre España, Francia, Suiza, Italia, Austria y Alemania, invitado por Gadamer, Szilazi, Löwith, Landgrebe, entre otros. En casa de Szilazi conoce a Michael Foucault, quien años más tarde le envía dedicado su obra Las palabras y las cosas. El 21 de junio se produce su reencuentro con Martín Heidegger. En ese momento su maestro se encontraba dando el curso titulado "Qué significa pensar" al cual Astrada asiste cuando el tiempo se lo permite. En ese país, Astrada pronunció conferencias en prestigiosas universidades.

A su regreso a la Argentina, tras la muerte de Eva Duarte de Perón, empiezan a surgir dentro del peronismo discrepancias en torno a la soberanía con John William Cooke, ${ }^{6}$ con quien Astrada mantenía una buena relación. Ambos sostenían que el movimiento debía avanzar en la lucha contra el imperialismo, cuestión en la que Perón no mostraba una clara definición. A este respecto Astrada escribirá un artículo llamado "Independencia incondicionada" en el que expresa su disconformidad con las últimas decisiones del presidente Perón.

En 1952 publica otra de sus obras capitales: La revolución existencialista. Hacia un humanismo de la libertad. Aquí, Astrada va a plantear que es indispensable el rescate del ser del hombre de la alienación para allanar el camino hacia su plenitud. La existencia humana es la guía de la humanidad, no hay nada exterior a ella. El devenir histórico es un camino hacía el hogar de la humanidad. Cada estirpe, con su propia identidad, se encamina hacia su destino planetario. Es por ello que el problema del ser nacional reaparece en sus obras, pues Astrada no aboga por una identidad universal, sino que cada pueblo debe tener la suya propia para comulgar con lo universal.

A partir de estos años el pensamiento de Astrada llega a tener altas repercusiones a nivel mundial. El filósofo brasileño Luis Washington Vita lo considera uno de los filósofos más importantes de nuestro hemisferio.

6 Diputado del primer período del peronismo. 
En tanto su pensamiento es incluido en dos de los clásicos diccionarios mundiales de filosofía: el de Nicola Abagnano y el de José Ferrater Mora.

En 1955, se produce el golpe de Estado que derroca a Perón. Obligado a volver a concursar sus cargos, Astrada decide retirarse de la facultad. Reanudada su relación con el Partido Comunista, realiza un viaje a la URSS. Allí brinda una conferencia titulada "El porvenir de la dialéctica" en donde polemiza con aquellas posturas que pretendían "revisar" el marxismo tras las denuncias de los crímenes cometidos por el régimen de Stalin. En ese período publica su libro Hegel y la dialéctica.

En el año 1957 verá la luz El marxismo y las escatologías, el cual erige a Astrada como un ferviente propulsor del marxismo y además lo sitúa entre aquellos defensores de las culturas autóctonas considerando el poder que hay en ellas para la construcción de una cosmovisión americana. Tras el rotundo éxito de este libro - unos 30.000 ejemplares vendidos a penas hiciera su aparición - la editorial Siglo Veinte publica al año siguiente su libro Marx y Hegel. Trabajo y alienación en la fenomenología y en los manuscritos.

En el año 1960 sale su libro Humanismo y dialéctica de la libertad. En esta obra plantea que el destino humano es un imperio sin fronteras. Si la historia es el recorrido de la conciencia hacia su libertad, de esta conciencia tiene que emerger el plan de lucha para la liberación total. Ese mismo año, por intermedio de Kordon, es invitado a visitar la República Popular China, en donde brinda la conferencia "Cultura, sociedad y política" y "La dialéctica y la simultaneidad de las contradicciones". Allí se produce su encuentro con Mao-Tsé Tung, en donde conversará con el líder chino sobre diversas cuestiones de filosofía política. De China parte para Moscú en donde pronuncia sus conferencias "El modelo occidental", "Anticolonialismo y convivencia de pueblos y culturas" y "El racionalismo, la paz y la democracia".

En el año 1961 escribe su libro Dialéctica y positivismo lógico en el que entra en polémica con aquellas corrientes filosóficas provenientes de el llamado Círculo de Viena. Esto será apreciado dos años más tarde por Raul Sciarreta y Luis Washington Vitta quienes ofrecerán sus respectivas críticas a la obra.

Dos años después sale Tierra y figura, en donde Astrada vuelve a hacer hincapié en la importancia de lo telúrico en el desarrollo de un programa político. América Latina tiene el mandato de su tierra de recuperar el acervo cultural que quedo acallado con la conquista. El llamado de la tierra que hiciera en otro momento volver al mismo San Martín a liberar 
a su pueblo es el que sigue latente y exhorta a las nuevas generaciones a la emancipación de América. También ese año aparece Ensayos filosóficos, el cual es una compilación de varios artículos de Astrada de diversas épocas de su periplo.

En 1964 reedita varias de sus obras, entre ellas El mito gaucho, en donde expresa su repudio al camino que ha seguido el peronismo.

En el año 1967 publica Fenomenología y praxis en donde continúa ahondando en las relaciones entre el movimiento fenomenológico y el materialismo histórico. En 1969 aparecen dos libros: La génesis de la dialéctica - En la mutación de la imagen de los presocráticos y Dialéctica e historia. Su último libro Martín Heidegger. De la analítica ontológica a la dimensión dialéctica es una recopilación de toda su labor respecto al filósofo de la Selva Negra y aparece en 1970, año en que el filósofo muere.

\section{ESTADO Y FILOSOFIA}

Nos proponemos demostrar aquí por qué Astrada realiza esta obra en esta época, y cuáles son los móviles que lo llevan ponerse a investigar sobre si hay una filosofía de la nación.

Si bien en sus comienzos Astrada fue un joven interesado en la filosofía universal, Juan Domingo Perón logró convencerlo, en su primer gobierno, de que su proyecto era auténticamente liberador para el pueblo argentino. Y es porque la asunción de este presidente representó de alguna manera la llegada a la condición de ciudadanos del pueblo, de los sectores más desposeídos de la Argentina. Tanto es así que entre 1945 y 1948 los salarios reales de los empleados públicos tuvieron un alza del 35 $\%$ y los de los obreros industriales subieron en un promedio del $50 \%$. Las cajas de jubilaciones pasaron de 300.000 afiliados en 1944 a 3.500.000 en 1949. Y se estableció por ley un fondo para otorgar pensiones a toda persona de escasos recursos mayor de 60 años no amparada por ningún sistema jubilatorio. También es de destacar la ampliación de derechos de los obreros, tales como jornada laboral de 8 horas diarias, indemnizaciones por despido, aguinaldo, vacaciones y disposiciones particulares sobre condiciones de trabajo; y de beneficios sociales como las colonias de vacaciones, planes de vivienda, distribución de indumentaria, juguetes y textos escolares. Los hospitales públicos duplicaron la cantidad de camas hospitalarias y las matrículas educativas crecieron a pasos agigantados.

En este contexto Astrada se erige como "filósofo de Estado" (DAVID, 2004, p.164), llegándose a convertir, en algunas circunstancias particulares, en una especie de "vocero" del presidente. Horacio González (1999) señala que Astrada creyó ver en Perón a aquel que captaría "el espíritu del pueblo". 
Espor elloque en estaépoca toda suproducción estáteñida porla esperanza que depositara en el entonces presidente. ${ }^{7}$ Durante los primeros años del peronismo, Carlos Astrada junto a un grupo de intelectuales como Leopoldo Marechal, Arturo Jauretche y Homero Guglielmini ${ }^{8}$ participaron activamente acompañando las principales decisiones del gobierno. Como resultado surgieron algunas publicaciones que incluían artículos de estos pensadores con temáticas que hacían referencia a los principales hechos políticos que atravesaba el país. Una de ellas fue "Argentina en marcha" la cual emerge de una llamada Comisión nacional de cooperación intelectual. También aparecerá en el año 1948 el folleto "Sociología de la guerra y filosofía de la paz" el cual fue pronunciado por el mismo Astrada ante la Escuela de Guerra Naval Argentina, fundamentando la "tercera posición" asumida por el Estado ante la Segunda Guerra Mundial. ${ }^{9}$ Estas argumentaciones están basadas en las posiciones de Immanuel Kant en su obra La paz perpetua y de Max Scheler en La idea de paz y el pacifismo. ${ }^{10}$ Astrada propone que las luchas entre seres humanos sean suprimidas por la lucha en común ante las cosas que dañan nuestra vida, contra el hambre, las injusticias sociales, los desastres naturales, el egoísmo, etc. En este marco llama a las fuerzas armadas a fortalecer "la paz interna sobre la base de la justicia

7 Esta mirada hegeliana de la realidad nacional ya había estado presente en la interpretación de Leopoldo Lugones del gaucho Martín Fierro. Lugones fue un polémico escritor por sus vinculaciones políticas, las cuales fueron desde el socialismo hasta el fascismo. Se lo reconoce por ser uno de los representantes del modernismo literario. Entre sus obras se destacan La guerra gaucha, Historia de Sarmiento y El payador. En 1913, en su conferencia sobre "El payador" caracteriza a la poesía gauchesca como la precursora de la formación de la conciencia nacional. Pero estas concepciones son utilizadas luego por el autor para justificar el golpe militar acaecido en 1930. De acuerdo a esto, González afirma que Astrada, si bien polemiza con Lugones políticamente, respecto a la interpretación del poema nacional, de alguna manera continúa su camino.

8 Leopoldo Marechal fue un prestigioso poeta y escritor, nucleado en la Revista Martín Fierro. Entre sus obras se destacan Canto de San Martín, Antígona Vèlez y Adán Buenosayres. Arturo Jauretche se ha destacado por su participación en el grupo FORJA y su consiguiente adhesión al peronismo. Además de ser un militante aguerrido, fue un destacado intelectual. Entre sus obras señalamos: El paso de los libres, Los profetas del odio y la Yapa y Manual de Zonceras argentinas. Homero Guglielmini fue un escritor y ensayista argentino, participante de la Reforma Universitaria y autor de Temas existenciales, Galeria espejos, entre otros.

9 Este texto es el que más críticas ha suscitado sobre la vinculación de Astrada al gobierno peronista. Su extremado compromiso lleva al filósofo a suavizar en estas líneas el genocidio de los indígenas llevado a cabo en la denominada "Campaña del Desierto". Por otra parte se trata de la primera vez en la historia argentina de que un filósofo, junto al presidente de la nación, se dirige a las Fuerzas Armadas fundamentando una postura de tamaña envergadura (Véase BUSTOS, 2011, "Sociología de la guerra y filosofía de la paz" en Cuadernos de Marte, n. 1 , Instituto de Investigaciones Gino Germani).

10 Estos dos filósofos habían sido tratados en conjunto también en el libro de Astrada La ética formal y los valores. Ensayo de una revalorización existencial de la moral kantiana orientado en el problema de la libertad, de 1938. 
social, y [...] con los pueblos hermanos del continente, de nuestra misma estirpe" (ASTRADA, 1948c, p. 19).

Otro texto que apareció en esa época fue "Fetichismo constitucional", en el cual, bajo el argumento hegeliano de que la Constitución es la conciencia de cada pueblo, se percibe el apoyo brindado por el filósofo a la reforma de la Constitución Argentina acaecida en el año 1949. ${ }^{11}$ Este trabajo está incluido en otro órgano de difusión con similares características que fue la revista Hechos e ideas. Siguiendo esta línea verá la luz Tribuna de la revolución, en donde se publicó el texto "Martín Fierro y el mito de los argentinos" que luego fue parte de El mito gaucho.

\section{LA OBRA}

El objetivo de este apartado es dar cuenta de la estructura de la obra a fin de que el lector pueda conocer la manera en que Astrada ha desarrollado la argumentación acerca de la existencia del mito gaucho.

La primera edición de El mito gaucho, publicada por Cruz del Sur en el año 1948 en la ciudad de Buenos Aires, consta de una pequeña introducción, en donde el autor afirma que es necesario indagar sobre lo que sea la "esencia argentina" y de dos partes tituladas "Raíz y estilo del hombre argentino" y "Martín Fierro y el mito gaucho". En la primera parte se afirma la proyección del hombre argentino en relación a su destino nacional. El paisaje, para Astrada, delimita el carácter del hombre y su relación con el mito. La tierra tiene un mensaje y mientras más de su tierra sea el hombre, más emparentado estará con la misión de su pueblo. Es por ello que el gaucho, al estar en el campo, puede comprender mejor la esencia de la argentinidad. También se hace alusión a las generaciones que negaron esta esencia y acallaron el mito que latía en la tierra. La promoción de la cultura europea hizo que se considerara a la cultura autóctona como algo despreciable y digno de ser acallado. Fuimos dominados por el extranjero incluso luego de la declaración de nuestra independencia. Es por ello que, según nuestro autor, es necesario retornar a la fuente originaria de la cultura argentina. Reafirmar su propia identidad es lo que permite a un pueblo recuperar lo que Astrada llama una "auténtica conciencia nacional" y de ese modo enfrentar a aquél que pretende dominarlo.

11 Esta constitución incorporaba los llamados "derechos de segunda generación" y establecía la igualdad jurídica del hombre y la mujer. También ampliaba el ámbito de la justicia militar y permitía la reelección indefinida del presidente. Fue derogada por la llamada "Revolución libertadora" en 1955. 
La segunda parte esta subdivida en tres secciones: "En la fuente del mito", "Cosmogonía gaucha" y "La cosmovisión política". En la primera de ellas Astrada trata de explicar por qué el personaje de Martín Fierro es una especie de héroe épico. Es decir, de qué manera este personaje se convierte en aquél que le toca vivir las injusticias sociales que lo alienan y extrañan para luego retornar, y por la fuerza del mito, delinear las notas del ser nacional. En la segunda sección Astrada intenta explicar cuáles son los saberes arcaicos que nutren al poema nacional en la cosmovisión que éste presenta. En la payada del gaucho Martín Fierro con el Moreno se puede percibir la presencia de conceptos pitagóricos, budistas e incluso de otras culturas autóctonas cuyos saberes se transmitieron generacionalmente en los habitantes originarios.

Uno es el sol, uno el mundo,
Sola y única es la luna;
Ansí12 han de saber que Dios
No crió cantidá ninguna.
El Ser de todos los seres
Sólo formó la unidá;
Lo demás lo ha criado el hombre
Después que aprendió a contar
(HERNÁNDEZ, 2005, p.192)

La tercera sección presenta el contenido político que tiene tanto el poema como su interpretación en la actualidad. De modo tal que plantea cuál es la misión de los argentinos en pos de la construcción de la comunidad nacional. Para ello Astrada analiza moralmente a cada uno de los personajes del poema, para mostrar qué sectores de la sociedad están representados por cada uno y qué es preciso hacer para lograr una comunidad en donde se respeten los derechos de todos los habitantes. El gaucho Martín Fierro, a pesar de las adversidades por las que ha pasado, ha podido sin embargo ofrecer a sus hijos los consejos de un sabio padre que promueve una sociedad justa para todos. Es por ello que Astrada promueve a mancomunar esfuerzos hacia la conquista de una conciencia nacional que, en comunión con su mito, sea prospectiva del bienestar general.

12 En castellano "así", Hernández conserva el vocabulario del gaucho en donde hay agregados y omisiones de letras en varias palabras. 


\section{EL MITO ARGENTINO}

Este apartado pretende arrojar luz al concepto del "mito de la nación". Astrada afirma que una nación no es simplemente un espacio, sino que es un conjunto de estados anímicos que conforman una comunidad, un pueblo que se siente propio por su esencia telúrica. Este sentimiento permanece y se trasmite de generación en generación a pesar de los avances de la vida moderna. No obstante los intentos de aniquilación de lo vernáculo, el mito de la nación aflora desde las entrañas de la tierra para dar su mensaje. Es así que el hombre argentino tiene una peculiaridad que está emparentada con su paisaje y sus antepasados, a pesar de la inmigración y de los intentos de dominación cultural europea que ha padecido. "Este despliegue de la modalidad argentina, devenir e incremento de su realidad histórica, arranca de un mito, que es tarea, es decir, prospección, el cernerse en el tiempo de una esencia" (ASTRADA, 1948a, p. 5-6).

El mito es susceptible de ser recuperado y trasvasado, pues emerge para incrementar su fuerza. Pide retornar porque, según Astrada, por obra de hombres que han buscado el progreso bajo la dicotomía de civilización y barbarie, se lo ha arrojado al olvido. Generaciones enteras que estuvieron cerca de los poderes de turno abogaron por importar todo tipo de modas extranjeras, despreciando la fuente originaria de la cultura argentina. Es así que aquello que define al hombre argentino, se presenta como lo más lejano en las circunstancias actuales. "[...] lo que lo define de modo esencial, su ser, es para él lo más remoto con relación a las cosas circundantes e inclusive a su persona física (Ídem, p.11)".

La pampa es extensa, misteriosa, desierta. Su desolación genera en el hombre que la habita un carácter disperso, errante. Pero, para Astrada este nihilismo es parte constitutiva del mito. Esta lucha con el paisaje ha delineado el carácter del héroe, ejemplificado por el gaucho Martín Fierro.

Estos rasgos y características, acendrados en un estilo típico de vida, el del gaucho, reclama el estro, la fuerza formadora, modeladora de los poetas. Nace así, nuestra poesía gauchesca, que, con insipiencia respecto al significado del mito, trata de interpretarlo, de estrellar su meollo, a través de sucesivas plasmaciones, de las que dan cuenta las obras de Hidalgo, Ascasubi y del Campo, hasta que nuestro mito logra su expresión máxima y esencial en el poema de Hernández (Ídem, p. 23).

De modo tal, afirma Astrada, el gaucho no es un mito sino que los argentinos poseen ese mito que emerge cuando la historia pretende ocultarlo. Cuando la clase dirigente se esmeró en negar y repudiar la cultura 
autóctona, el grito de la tierra se hizo escuchar: "[...] una sombra de olvido se cierne sobre la pampa [...] y el protagonista anónimo de nuestra epopeya es tan solo un paria..." (Ídem, p. 25); este paria, sin embargo, contiene una fuerza indisoluble: el germen de la nacionalidad. El gaucho cumplirá su karma que no es otro que someterse a la ley de su propio destino. Frente a lo que le ofrece el mundo moderno, su sentimiento es de apatridad, de enajenación, puesto que este mundo se ha dedicado a importar modas extranjeras que nada tienen que ver con su ánimo vernáculo.

Espoleado por la infidelidad a su extracción histórica y estilo humano, se hizo inquilino de productos culturales sistematizados por otra forma de existencia, y en la cual fue sólo huésped, o mejor, buscó refugio en su fuga de sí mismo (Ídem, p. 35).

Es de notar que, para Astrada, el hecho de poseer un poema como el de Hernández constituye un privilegio para los argentinos frente a los demás habitantes de América Latina. ${ }^{13} \mathrm{Y}$ es porque el personaje de Martín Fierro, en "La vuelta", deja el legado de construir una comunidad justa y libre en donde los habitantes de esa nación no tengan que pasar por las vicisitudes que tuvo que atravesar él mismo.

Para él son lo calabozos

Para él las duras prisiones En su boca no hay razones Aunque la razón le sobre Que son campanas de palo Las razones de los pobres (HERNÁNDEZ, 2005, p. 44).

Al delinear las notas esenciales de una nación, surge el gaucho como protagonista de la historia, pues Astrada traerá a colación la frase de Hölderlin "lo que perdura lo instauran los poetas" (ASTRADA, 1948 a, p. 82). Es así que Hernández representa aquel poeta que supo nutrirse de la sabia del mito de la nación para expresarlo con la epopeya de Martín Fierro. El gaucho es presencia y continuidad de un estilo de vida gentilicio que tiene una misión que cumplir.

\footnotetext{
13 No obstante es preciso recordar que en la misma época de la obra de Astrada se publica Muerte y transfiguración de Martín Fierro, de Ezequiel Martínez Estrada quien plantea que mitologizar al gaucho es contribuir al encubrimiento de la realidad social. Borges, unos años después, si bien no lo plantea en esos términos y coincide con Astrada en que el Martín Fierro podría ser interpretado como un poema épico, afirma que todo lo que hay para decir sobre el poema, ya está escrito en la obra de Martínez Estrada. Cabe señalar que esta última consta de casi mil páginas en las que se analiza filosófica, sociológica, historiográfica y literariamente cada párrafo del poema. En la segunda edición de El mito gaucho, Astrada hace referencia a estas interpretaciones calificando a sus de autores de "malos periodistas de la historia y ciegos para la valoración cultural" (ASTRADA, 1964, p. 21). Véase BUSTOS, 2010, "Martín Fierro Filósofo: Carlos Astrada y Ezequiel Martínez Estrada en el anverso y reverso del poema nacional" en Revista Científica de la Uces, Vol. XIV, n. 2, 2010, Buenos Aires.
} 


\section{EL GAUCHO MARTÍN FIERRO COMO HÉROE}

Aquí pretendemos dar cuenta de la consideración del protagonista del poema como un héroe épico, a fin de mostrar el carácter universal de ese poema y de su interpretación en la historia.

El concepto de héroe en la obra de Carlos Astrada tiene influencias de Hegel y de Heidegger. Para el primero, los héroes son los grandes hombres que conducen a los pueblos hacia su destino universal. "Lo que hacen es lo justo" (Ídem, p. 62), porque sólo ellos están llamados a cumplir esa misión. Estos individuos son convocados a realizar algo fuera de lo común, pues la vida cotidiana y simple no los complace. Si bien no buscan la dicha, sólo acuden al llamado que oyen desde sus entrañas. Lo que son es su obra, su punto máximo es el esfuerzo y la lucha.

Para Heidegger, la constitución del Dasein ${ }^{14}$ se halla atravesada por la historicidad. Esta historicidad deviene en una temporalidad extática en donde pasado, presente y futuro confluyen en un éxtasis único. Quiere decir que cada hombre es aquello que fueron sus antepasados y lo que va siendo en su devenir. Pero el futuro es la parte más importante ya que cada uno es un proyecto que tiende hacia un destino. La anticipación del futuro es lo que determina el horizonte de posibilidades de cada hombre. Por lo tanto las posibilidades de cada uno van configurando el ser de cada cual de acuerdo a aquéllas que cada uno va eligiendo. Pero la única posibilidad inminente es la muerte. Por lo tanto es necesario asumir esta posibilidad ya que es la que le pertenece a todos indefectiblemente. En este sentido sólo aquél que asuma el legado del vivir hacia la muerte puede resolverse en cumplir el destino de la finalidad plenaria, del acontecer del pueblo. La resolución heideggeriana es la firme decisión de dejar de lado la vida cotidiana, el das Man, ${ }^{15}$ que implica la diversión y la distracción; para lanzarse a comprender el mundo tal como es. La única manera de asumir el destino es enfrentarse a la posibilidad más propia, es decir, a la muerte. Una vez liberado del enfrentamiento de la muerte puede el Dasein compartir con los demás un destino común y salir a luchar para alcanzar su plenitud y la de su pueblo.

14 Heidegger no se refiere a los hombres, sino al Dasein, como ahí del Ser. Esto quiere decir, cada hombre en tanto el ente capaz de comprender el Ser, por medio del cual el Ser se manifiesta (Véase BUSTOS, 2007, "Astrada y Heidegger: La presencia de Sein und Zeit en "El mito gaucho" en Aghora Philosóphica. Revista marplantese de Filosofía, Vol. VIII, n. 15).

15 Rivera traduce este concepto como el "Uno" que es el impersonal en que nos movemos en nuestro mundo circundante, es el plano de cotidianeidad en la que se manejan todos los hombres, cuyo saber es el del sentido común sin fundamentación (Veáse HEIDEGGER, 1997. Ser y tiempo, Santiago de Chile: Editorial Universitaria). 
Es con este bagaje conceptual con el que Astrada encarará la búsqueda de aquellas personalidades argentinas que de alguna manera puedan constituirse en los héroes o modelos a seguir. "A los argentinos, Martín Fierro nos deja, como precioso legado, toda una concepción de la vida y asimismo una concepción política de la estructura y lineamientos esenciales de nuestra comunidad nacional" (Ídem, p. 52)

Para Astrada, el personaje de Martín Fierro constituye el ejemplo del gaucho que luchó por la independencia nacional. Especialmente en el análisis de "La vuelta", Astrada vislumbra un proyecto nacional que está presente en los consejos que el personaje de Fierro les diera a sus hijos.

Siguiendo a Hegel, el filósofo afirma que todo pueblo tiene una misión que cumplir en función de su destino. Y para participar de lo universal, es necesario primero congeniar con lo nacional. Para Astrada, la fuerza de la Argentina no está ni en los capitales ni en los monopolios, sino en la tierra. Aquí aparece la mística rilkeana que campea toda su obra. Las poesías de Rainer María Rilke acompañan a la reflexión de Astrada muy cercanamente. La tierra tiene un carácter determinante y, junto con Nietzsche, Astrada reclama la afirmación de la misma. Por ello el gaucho, al ser el que más familiarizado está con la tierra, es capaz de comprenderla y asumir su mandato. La insurrección agraria estará presente en toda la obra de Astrada como la posibilidad de la emancipación de los oprimidos. Los ideales de justicia, igualdad y libertad proclamados en "La vuelta" serán alcanzados mediante el rumbo que marcará el gaucho.

Astrada denuncia que existe una intencionada indiferencia respecto de la cultura argentina y por ello es necesario retomar el mito gaucho a fin de poder rescatar aquello que hace a los argentinos miembros de la misma comunidad para poder, de esa manera, participar todos en un proyecto común. Con lenguaje heideggeriano afirma Astrada que "el hombre argentino es una tarea" (Ídem, p. 5). Y su legado está en reactualizar ese pasado que lo define.

Porque es el carácter, junto con la continuidad en el esfuerzo, con la constancia en la persecución de los fines propuestos a la voluntad, lo que define la personalidad, le da sello y la enfrenta productivamente, con impulso creador, a una tarea, a una obra digna de los desvelos humanos y del destino y de las esperanzas de la comunidad a que ella pertenece (Ídem, p. 8).

\section{EL MITO AMERICANO}

En este apartado pretendemos demostrar cómo Astrada abre el horizonte hermenéutico de interpretación del mito, pensando en toda la 
América Latina, encontrando en los saberes arcaicos importantes mensajes que emergerían desde la tierra.

Casi diez años después de la primera aparición de El mito gaucho, Astrada vuelve a referirse al mito, pero esta vez este concepto irá cobrando más carácter revolucionario. ${ }^{16}$ El marxismo y las escatologías es la obra en la que el filósofo muestra su convicción de que el materialismo histórico es la forma por antonomasia de entender la sociedad. Así afirmará en su prólogo: “[...] el marxismo entraña la visión más honda y certera de los problemas cruciales que la infraestructura económica plantea a todas las sociedades" (ASTRADA, 1957, p.9). Pero no por ello dejará de seguir ahondando en la fuerza del mito. El mito ha surgido desde la impotencia del hombre ante la naturaleza. Es por ello que emerge antes de todo saber, cooriginariamente con la filosofía. "El mito es el amanecer de la reflexión filosófica acerca del mundo" (Ídem, p. 11). Pero no es el resultado de un alma individual, sino que posee un transfondo colectivo. Es por ello que el mito está siempre emparentado con la historia, pues adquiere significación expresa en el devenir. El relato mítico alude a un pasado remoto que reaparece para revivirse y resignificarse en el tiempo. De este modo, plantea Astrada que las culturas míticas no conciben un tiempo lineal sino que hay etapas, las cuales están separadas unas de otras. Para Astrada, el mito no es histórico, sino que sería prehistórico. Pertenece a un pasado sagrado. Para la mentalidad mítica la realidad reside en ese momento sagrado, el cual tiene una potencia creadora que opera en el devenir. Es así que el hombre mítico constituye un arquetipo a seguir.

Astrada afirma que en América Latina las culturas arcaicas habían adquirido un gran desarrollo. Consecuentemente, el genocidio contra el aborigen constituyó un atentado al patrimonio cultural de la humanidad.

No se estuvo en presencia de bárbaros, sino frente a culturas del mismo linaje de aquella de la cual procedían los conquistadores, la que ocultaba la verdadera barbarie en más de una de sus formas, entre éstas la codicia y la crueldad (Ídem, p. 47).

16 Es notable que del alejamiento de Astrada del peronismo no haya algo expresamente documentado, si bien podría inferirse de la lectura de la segunda edición de la obra a la que hacemos referencia, que la negativa de Perón de resistir con armas el golpe de Estado sería el punto en el que Astrada rompe con el movimiento desde lo que podría darse en llamar una postura "evitista" (Véase, p. 13). 
Las culturas míticas americanas ${ }^{17}$ habían desarrollado la idea del eterno retorno. Esto reaparece en el Martín Fierro cuando se hace referencia al tiempo como una rueda eterna. Aquí Astrada ve la fuerza de lo telúrico emergiendo en el poema nacional.

Lo acontecido en el suelo de América influye, sin duda, en su pensamiento y en su arte y esto nos conduce a pensar que la veta emocional que todavía aflora de lo americano autóctono no se ha perdido del todo (Ídem, ibídem).

De este modo, el filósofo exhorta a aunar esfuerzos entre la antropología, la etnología y la filosofía a fin de otorgarle a la cultura argentina el lugar que le corresponde en el universo cultural. Occidente se ha encargado de desmantelar, en nombre del engrandecimiento de su imperio capitalista, todo tipo de culturas. Pero el mito soterraño emerge una y otra vez. Asistimos, para el filósofo, al ocaso de Occidente y el escenario está listo para la emergencia del hombre nuevo.

Justamente porque comienza una nueva época histórica de dimensión planetaria y el mundo en su estructura social y humana, con todas sus facticidades subyacentes, se encuentra en plena transformación, encaminándose con ritmo acelerado a una unidad múltiplemente diversificada, no puede ser Occidente el lugar inicial de la historia verdadera (Ídem, p.132).

En el año 1963 el pindárico "deviene el que eres" volverá a aparecer en su obra Tierra y figura. Si El mito gaucho pretendía encontrar el germen de la nacionalidad, esta obra va a estar dedicada a deducir cuáles son los mensajes que la tierra americana tiene para el hombre nativo. ${ }^{18}$ Astrada cree fervientemente en las potencias de las culturas arcaicas para delinear la misión de los pueblos americanos. El espíritu de estas gloriosas civilizaciones circula por la tierra y el aire, alimentando a las nuevas generaciones en el anhelo de vivir en plenitud.

[...] esas culturas destruidas en su armazón y en su soporte humano, pero no del todo extinguidas, nos envían desde su rota arcilla, ahora y siempre, junto con su mensaje, que se irá descifrando poco a poco, el poderoso aliento telúrico que nos envuelve y nos ata con fuerza de raíces vivas todavía indisolublemente a ese pasado y a la tierra en que esas culturas florecieron (Ídem, p.14-15).

17 Así se denomina un artículo de Astrada que fue publicado en Norte revolucionario, la revista del Frente Indoamericano popular, dirigida por Mario Roberto Santucho, con quien Astrada cultivó una exigua amistad (Véase nota al pie n. 4).

18 "Ya en el paideuma de la cultura quechua se le asigna al hombre tal vínculo con lo telúrico, y es así que se lo concibe y define como 'tierra que anda' " (ASTRADA, 1963, p.10). 
La vida moderna aparenta ofrecer el libre acceso a todo tipo de bienes. Pero esa igualdad del mundo capitalista atenta contra la identidad de cada estirpe y encubre la desigualdad de derechos que existe en la actualidad. Otro tanto pasa con la libertad, pues se es libre de comprar lo que el sistema ofrece, dentro de las posibilidades de cada uno. Pero una de las notas esenciales de la libertad, según Astrada, es que el hombre se encuentre identificado con lo que hace. Es por ello que el filósofo argentino comparte con Heidegger la idea de apatridad del mundo moderno. ${ }^{19}$

Una nueva libertad, creada por el soplo de las grandes afirmaciones vitales, se abre paso en el mundo. Es una libertad de signo positivo que consiste en imponerse a sí mismo la ley inherente a la progresión de cada sociedad en el ámbito histórico de su cultura (ASTRADA, 1963, p. 20).

San Martín es, para Astrada, el hombre que ha buscado la libertad del pueblo argentino bajo la máxima de ser sí mismo. El héroe del mito hará su aparición, y esta vez en lugar de ser la pampa serán los andes los que constituyan el paisaje originario. Por más que se halle en el extranjero San Martín no desconoce cuál es su origen y en este reconocimiento siente el llamado de la tierra a cumplir su misión. De modo tal que Astrada plantea que los argentinos se encuentran ante "el supremo arquetipo de la argentinidad" (Ídem, p. 29).

Astrada postula que la máxima de San Martín se remonta a la Grecia de Platón. La exhortación a conocerse a sí mismo no era otra cosa que el buscar el propio destino. La teoría de la reminiscencia por la cual las almas pasaban antes de nacer por el Leteo en el cual olvidaban quiénes eran sigue hoy en pie. El mito aflora para recordar al hombre hacia dónde debe ir. Pero ahora esa teoría es reemplazada por la categoría de historicidad. ${ }^{20}$ El mito intentaba dar cuenta de que los hombres eran en parte lo que sus antepasados habían sido y que debían por lo tanto responder a un destino en común. De este modo, el carácter histórico del ser humano, tal como lo expusiera Marx, ha venido a reemplazar al mito.

El pensamiento de Platón acerca de estas nociones fundamentales, que partió de un mito, hoy con otro alcance y sentido más terrenos- es una verdad no sólo filosófica, sino incluso científica (Ídem, p. 30).

19 Véase ASTRADA, 1952 La revolución existencialista. Buenos Aires: Nuevo Destino, 1952.

20 Se refiere al concepto heideggeriano de historicidad explicado más arriba. 
San Martín es el héroe que lleva todas las características épicas. Por lo tanto no es un santo, sumisión no es hacer el bien, sino aquello que tiene que hacer. Perosu obra es digna de ejemplo. Esteejemplo, asevera Astrada, noes sólo digno de ser repetido en la actualidad, sino que tiene un carácter aleccionador para las generaciones futuras. Por ello es que en su vida será presa de largos reproches, pues San Martín no busca la fama y el honor entre sus contemporáneos, sino que sabe que su misión tendrá una valoración intempestiva.

Astrada señala que, encontrándose en Europa, San Martín fue invocado por el grito de la tierra a cumplir su destino. Esa fuerza cobra vida cuando el temple anímico del lugar se transforma en esencia operante. El concepto de héroe aparece aquí con las características mitológicas. No es un ser perfecto ni enteramente bueno, sino que es el que hace lo que tiene que hacer. La autenticidad es su norte, es por ello que no hay un mínimo atisbo de renunciamiento. De este modo, Astrada encuentra en él el influjo de la ejemplaridad.

[...] desdequeéstanosóloincideen elpresente, suscitandoadmiraciónyamor, sinoqueseproyectaaleccionadorayorientadorahaciaelfuturoatravésdeuna superposición temporal de devociones colectivas, que es en lo que consiste la posteridad histórica de los genios, los héroes, los fundadores (Ídem, p. 41).

\section{LA VUELTA DEL MITO GAUCHO}

Nos centramos nuevamente en la obra, esta vez editada varios años después con importantes cambios, para vislumbrar que las tesis principales del trabajo original se mantienen intactas. El mito es la fuerza propulsora de los pueblos y es lo que hace posible el sentimiento de pertenecer a una nación y el ansia por participar en ese destino en comúnEn el año 1964 vio la luz la reedición de El mito gaucho, con una gruesa introducción en donde se puede advertir el alejamiento total de Astrada del peronismo. Decididamente declara que los ideales de Martín Fierro no provienen de otro lado que de las culturas arcaicas precolombinas. El gaucho constituye el híbrido en donde se concentra el indio y el extranjero. Por ello es que tiene una ascendencia dual. "[...] la hormona vital de la liberación sólo circula en la corriente sanguínea de los criollos cuyo ancestro telúrico es el gaucho, ya injerto en el indio" (ASTRADA, 1964, p. 40).

La libertad es el valor por antonomasia que defiende el Martín Fierro. De allí que Astrada señale que la vía de la liberación no es otra que la insurrección agraria. El gaucho, afirma, tiene la misión de vengar al aborigen destruido. Esta venganza encierra la lucha de los oprimidos contra 
el sistema imperialista que ahogó la fuerza vital de la estirpe y sigue subyugando lo poco que queda de ella. Astrada propone, así, la conformación de una gauchocracia comunitaria que consista en una colectividad afín a su teluria y a su historia. Para ello será necesario que el mito renazca con su potencia creadora. "Lo real del mito acude, para su expresión, al logos poético" (Ídem, p.43). El mito se crea en la formación de un pueblo. Y un pueblo se forma con un ideal de colectividad en prospección hacia el futuro. Por ello el mito persiste marcando el rumbo que éste ha de tomar.

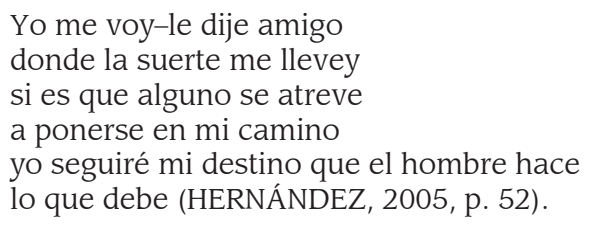

Es importante destacar que en esta segunda edición aparece la mención a la campaña del Desierto, a la cual Astrada caracteriza como un verdadero genocidio. En efecto se encarga de relacionar directamente la suerte que corrieron los indios con la de los gauchos. Del genocidio del aborigen, sostiene, sacaron provecho las familias que luego constituirían la oligarquía que profundizó las injusticias contra el gaucho. Así, en la unidad de ambos grupos desposeídos, se constituyeron los ejércitos más valientes que lucharon por la libertad nacional.

Nuestros soldados de la guerra de la emancipación supieron morir y vencer en una causa noble, dándonos, por lo menos, la independencia política. Pero ellos eran gauchos; gauchos eran también los que formaron el Regimiento de Granaderos a Caballo de San Martín (Ídem, p.18).

El mito puede convertirse en acción social que tienda hacia el cambio radical. Tal ha sucedido en la independencia argentina y se vislumbra también en las grandes revoluciones, como la francesa, la rusa y la china. Esta última, encarna para Astrada el acicate de la lucha final. Estas revoluciones muestran que la fuerza del mito arcaico puede penetrar en las conciencias de los hombres para cumplir su destino de vivir en plenitud. Porque, según nuestro autor, todo mito está signado a llevar a la plenitud a quien lo protagoniza.

Como señalamos más arriba, Astrada, siguiendo a Heidegger, afirma que el mito resurge ejerciendo diferentes direcciones en determinadas épocas. Es por ello que el hombre siempre puede elegir nuevos héroes. Desde este argumento en esta segunda edición de El mito gaucho podrá Astrada realizar una interpretación absolutamente diferente de la figura de Perón, esta vez analogándolo deliberadamente al personaje de Vizcacha. 
Pasado cierto tiempo, una década escasa, se comprobó, empero, que el segundo óbito del Viejo Vizcacha fue, tras un simple letargo, sólo aparente, y que el pueblo -el proletariado- engañado, carente de conciencia de clase, había sido víctima de un ominoso paternalismo, el cual le impidió adquirir una ideología orientadora. Fue fraudulentamente enfervorizado por un seudo jefe, con aparotisidad de revolucionario, el que, ante la primera amenaza, por sugestión de la oligarquía castrense y por propia cobardía, huyó al extranjero (Ídem, p. 118-119).

En virtud de ello, Astrada exhorta a la conformación de un "auténtico pueblo" que protagonice su destino aunando los esfuerzos de los núcleos que expresan su descontento. Citando a Renán dirá que "una Nación, en lo que atañe a su vigencia histórica y a su futuro, es siempre, un plebiscito cotidiano" (Ídem, p.126). Astrada considera en este punto que aun no se ha conformado un pueblo con todas las características que debe tener un pueblo nacional. Hace falta la voluntad de compartir una tradición y unos principios que lleven el destino de la nación. El pueblo aun no está protagonizando el devenir de la nación, sino que sigue encontrándose sujeto a los grandes núcleos de poder.

Si Martín Fierro tiene el poder de reunir a los argentinos, ya que expresa el sufrimiento de los oprimidos, es necesaria la unidad de este pueblo para luchar contra aquéllos que han basado todo su poder en esa opresión.

Aunque muchos creen que el gaucho tiene un alma de reyuno, no se encontrará ninguno que no le dueblen las penas; mas no debe aflojar uno mientras hay sangre en las venas (HERNÁNDEZ, 2005, p.37).

En consonancia con estos postulados Renán afirma que "el haber sufrido, gozado y esperado juntos vale más que las aduanas comunes y las fronteras adecuadas" (RENÁN, 1947, p. 40). De modo que es preciso reafirmar esos lazos a fin de reconducir el destino del pueblo. Estas ideas le permiten a Astrada ampliar su horizonte hacia toda Latinoamérica. Del encuentro cultural latinoamericano, surgirá el paideuma que dará el aliento a una cosmovisión renovadora del estado de cosas actual.

El sagitario de esta hazaña será el pueblo politizado, consciente, solidario, pero el norte de su acción le será señalado por una doctrina y un ideal de liberación, con el cual él se haya identificado a través de conductores auténticos, lúcidos y serenos (ASTRADA, 1964, p.127).

Así, el héroe del mito se irá desplazando hacia los líderes revolucionarios de los años sesenta. La entrevista que tuviera el filósofo con MaoTsé Tung será una de las claves para vislumbrar ese viraje. Luego su 
relación epistolar con Mario Roberto Santucho dará cuenta del tipo de héroe que le interesa reconocer al filósofo a fin de lograr la guía que el pueblo necesita. Pues es necesario realizar una omnicomprensión integral de todas las efectivas virtualidades de los hombres a fin de poder construir las bases sociales para el desarrollo pleno de todos. Esta comprensión no va a decantar en un ideal, sino que se irá desenvolviendo en la praxis. Para ello es indispensable que el hombre esté enraizado en una comunidad nacional. Es que sólo desde la comunidad nacional se puede pensar políticamente la comunidad universal, pues la nación es la que establece el nexo orgánico de las culturas y de los ideales.

Si la cultura se nutre del sustrato viviente de la comunidad política, en lo nacional y en lo universal, entonces la tarea formativa, cuando es auténtica, está de suyo implicada en el proceso por el cual y en el cual aquélla se hace y deviene hacia la plenitud de su sustancia y de sus formas" (ASTRADA, 1952, p. 181).

La formación debe ser una praxis en la que cada hombre certifique que es un fin en si mismo y no medio para otra cosa, tal como le había hecho creer la moral capitalista. Asentado este conocimiento, todos los valores de las cosas se modifican. La formación política es formación espiritual. Astrada exhorta en este punto a retomar los ideales de principio de siglo en los que se propone una formación integral de la persona, considerada como sujeto político, "[...] siempre dispuesta a actuar y decidirse, en función social, por el pueblo y el ideal histórico de la comunidad política" (ASTRADA, 1952, p. 187). El pueblo político debe ser el fundamento del Estado y, por lo tanto, como protagonista de la historia, debe tomar las riendas de la sociedad. Así como cada pueblo tiene su contenido espiritual, este contenido infunde en cada hombre el compromiso político de que ese pueblo pueda vivir en plenitud.

Astrada considera que la época actual es un momento crucial en donde una nueva imagen del hombre se erige frente al mundo. Ya no se trata de pensar un sujeto aislado del mundo, frente a un objeto a conocer. Sino que el hombre es en cuanto ser en el mundo, está comprometido con él, consignado. Es por tanto el protagonista de la historia y el encargado de cambiar el rumbo de las cosas. Es el hombre nuevo que aflorará cambiando todas las reglas de juego. El hombre nuevo que no es otro que aquel que se ha encontrado a sí mismo. 


\section{CONCLUSIÓN}

Hasta aquí hemos podido mostrar de qué modo esta obra es susceptible de reinterpretarse a fin de aportar a la reflexión sobre la delimitación de la nacionalidad. Y es que, según nuestro autor, el mito resurge una y otra vez, eligiendo nuevos héroes que puedan llevar a cabo la misión de conducir a su pueblo hacia su destino propio. Esto es lo que permite que esta obra pueda ser reinterpretada no sólo desde su autor sino desde cualquier lector que encare este proyecto. El mito de la nación puede ser revalorizado porque tiene que ver con la tradición de un pueblo y ésta vive incrementándose permanentemente en el devenir histórico. Es por ello que el diálogo con los orígenes de un pueblo nunca encuentra un punto de culminación porque se alimenta de las concepciones y vivencias de cada miembro de la comunidad.

Astrada afirma que el mito es la fuerza que impulsa a la humanidad a desarrollar todas sus potencialidades. Esto es lo que le interesa y a lo que apela cuando cree ver en el peronismo el movimiento de masas que auténticamente configurará el pueblo argentino.

Pero si bien pronto se aleja del peronismo, sigue insistiendo en que el mito siempre retorna para vivificar las virtualidades de los seres humanos y conducirlos hacia su plenitud. Es así que afirma que las grandes revoluciones de la humanidad no podrían haber acontecido sin la fuerza del mito, y que éste es la esperanza de los hombres para lograr un cambio radical.

En efecto, en la segunda edición encontramos una interpretación diferente, en donde aparecen nuevos héroes capaces de captar el espíritu del pueblo y conducirlo a su destino. De este modo Astrada exhorta a una formación humana que esté centrada en el conocimiento de todas las culturas que habitaron el suelo argentino, con el objeto de configurar una comunidad afín a su teluria. Esto no podrá realizarse sin la fuerza del mito, pues es el motor que los pueblos necesitan para defender su destino común.

\section{BIBLIOGRAFÍA}

ASTRADA, C. El mito gaucho. Buenos Aires: Cruz del Sur, 1982a; Buenos Aires: Docencia, $1964 / 1948$ a. Aires, 1948 b.

"Fetichismo constitucional" en Hechos e Ideas. año IX, n. 55. Buenos

Sociología de la guerra y filosofía de la paz. Buenos Aires: Instituto de Filosofía y Letras, 1948c. 
."Los modelos personales y la hipóstasis del valor. Sugestiones para un personalismo ético". Cuadernos de filosofía. año II, fasc. IV, Buenos Aires: Facultad de Filosofía y Letras, 1950.

La revolución existencialista. Buenos Aires: Nuevo Destino, 1952. ."Mito, tiempo e historicidad" en Cuadernos de filosofía. Buenos Aires: Instituto de Filosofía, Universidad Nacional de Buenos Aires, 1953. El marxismo y las escatologías. Buenos Aires: Procyon, 1957. Tierra y figura, Buenos Aires: Ameghino, 1963. ."Realismo de la utopía". en Kairós, año II, n. 4, Buenos Aires: Devenir, 1968.

BORGES, J. El “Martín Fierro”. Buenos Aires: Columba, 1953.

DAVID, G. "A la búsqueda de un sujeto político. Las afinidades electivas de Carlos Astrada". Políticas de la Memoria, n. 4, Buenos Aires: Cedinci, 2003 / 2004.

2004.

Carlos Astrada. La filosofía argentina.Buenos Aires: El Cielo por Asalto,

GONZÁLEZ, H. Restos pampeanos. Buenos Aires: Colihue, 1999.

HEGEL, G. Lecciones sobre filosofía de la historia. México: FCE, 1995.

HEIDEGGER, M. Ser y tiempo. Santiago de Chile: Ed. Universitaria, 1997.

HERNÁNDEZ, J. Martín Fierro. Buenos Aires: El Libertador, 2005.

MARTINEZ ESTRADA, E. Muerte y transfiguración de Martín Fierro. Rosario: Beatriz Viterbo, 1948 / 2005.

PERÓN, J. La comunidad organizada. Buenos Aires: Ediciones Evita, 2004.

RENÁN, E. ¿Qué es una nación?. Buenos Aires: Elevación, 1947.

VERNIK, E. Mito y utopía en Astrada. Pensamiento de los confines, n. 15, Buenos Aires: FCE, 2004.

Carlos Astrada: La nación como mito y traducción. Tensões Mundiais, v. 6. n. 10, jan./jun. 2010, p. 35-53, Fortaleza (no prelo). 


\section{A imagem de modernidade brasileira: Collor e a eleição de 1989}

Grazielle de Albuquerque Moura Paiva

A autora analisa a relação entre o jogo político-eleitoral e a percepção de modernidade entre os brasileiros a partir do caso da eleição de Fernando Collor, no final da década de 1980. Seu material empírico é constituído de reportagens que projetam o candidato como um jovem, dinâmico, ousado e corajoso inimigo da corrupção.

Palavras-chave: Eleições de 1989 , Fernando Collor de Mello, Democracia Brasileira, Modernidade.

Grazielle de Albuquerque Moura Paiva: Jornalista, mestranda em Políticas Públicas e Sociedade (MAPPS) pela Universidade Estadual do Ceará, pesquisadora do Observatório das Nacionalidades.

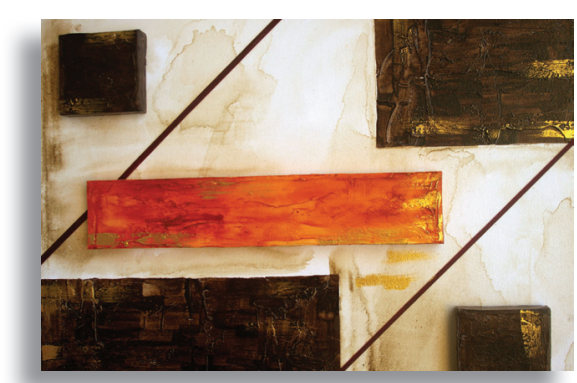

The image of the Brazilian modernity: Collor and the 1989 election

The author analyzes the relationship between the political-electoral game and the perception of modernity among Brazilians from the case of the election of Fernando Collor in the late 1980 's. His empirical material consists of reports projecting the candidate as a young, dynamic, bold and courageous enemy of corruption.

Key words: 1989 Elections, Fernando Collor de Mello, Brazilian Democracy, Modernity. 